Received: June 29, 2017

Revision received: March 12, 2018

\title{
Analysis of Spatial-temporal Distribution, Focus Trends and Evolution of Sports Culture Education Research in China*
}

\author{
Yuanguo Liu ${ }^{1}$ \\ Shenyang Sport University
}

\author{
Xin Wang ${ }^{2}$ \\ Shenyang Sport University
}

\begin{abstract}
Based on the bibliometric method, 770 papers on sports culture education collected in CSSCI on CNKI since 1998 were visualized, and the scientific knowledge graph was drawn by the CiteSpace V visual analysis software to study the number of papers on sports culture education, scientific research institutions, authors, research focus and evolutionary processes to further gain an overall understanding of the trends and dynamics of sports education research in China, which provides a reference for the direction of sports culture education research. Research conclusions: Firstly, the research on sports culture education in China began in 1998, and the number of publications reached the peak in 2014, which afterwards still remained high despite slight decline. Secondly, normal colleges and universities are the main force for the research on sports culture education. Thirdly, in terms of the evolutionary process, the research on sports culture education continuously keeps eyes on school sports, and transfer its focus to the competitive sports and mass sports at the later stage, indicating that sports culture education is a systematic project involving the entire population and requires the participation of the whole society.
\end{abstract}

\section{Keywords}

Sports Culture Education • Knowledge Graph • Spatial-Temporal Distribution • Evolutionary Process • Sports Education $\cdot$ School Sports

\footnotetext{
* The Youth National Social Science Fund of China: Study on the intergenerational conflict of sports culture under the background of cultural power strategy (17CTY008); The Basic Scientific Research for Youth Project of Universities in Liaoning: Study on monitoring mechanism of "National Student Physical Health standard "implemented in compulsory education stage by Liaoning (WQN2017ST13); Planned Project of Supporting Innovative Talents in Colleges and Universities of Liaoning Province in 2017 (WR2017015)

${ }^{1}$ Physical Education Department, Shenyang Sport University, Shenyang 110102, China. Email: 83970220@qq.com

${ }^{2}$ Correspondence to: Physical Education Department, Shenyang Sport University, Shenyang 110102, China. Email: Zhenguo1717@sina.com
}

Citation: Liu, Y. G., \& Wang, X, Analysis of Spatial-temporal Distribution, Focus Trends and Evolution of Sports Culture
Education Research in China. Educational Sciences: Theory \& Practice, 18(5), 2195-2205.
http://dx.doi.org/10.12738/estp.2018.5.119


At the National Education Science Conference held on September 10, 2018, General Secretary Xi Jinping emphasized that "we must establish a health-first educational philosophy and set up comprehensive physical education curriculum to help students enjoy their physical fitness, enhance their health, perfect their personality, and temper their will." This marks the promotion of sports culture education to a new high, highlighting the necessity of sports culture education in today's sports undertaking. This paper, with the papers on sports culture education included in the CNKI database as the research object, drew the knowledge graph of sports culture education by the visual analysis tool CiteSpace $\mathrm{V}$ software, to understand the process, characteristics and frontier areas of sports culture education research in China and analyze the focus and evolutionary process of sports culture education research, which will serve as a fundamental reference for further sports culture education research.

\section{Data Source and Research Methods}

\section{Data source}

The Bradford literature discretization law shows that most of the key literature are usually published in a few core journals. This paper selected the source of the literature data as CNKI. The search followed the rule of subject = "sports culture" and "education". All papers from CSSCI so far were searched on November 8, 2018, and 783 papers were obtained. With papers non-related to the subject, there were 770 valid papers in total. According to the search, the earliest papers on sports culture education were published in 1998. Therefore, the papers selected in this paper were published from 1998 to 2018. The above papers were exported in the text form of "RefWorks" and "Endnote" respectively, the former for visual analysis and the latter for filing and statistics of word frequency.

\section{Research methods}

Bibliometric method. The bibliometric method, initially proposed by American scholar A. J. LotKa, is a method for quantitative statistics of the number, timing sequence and spatial distribution of literature using mathematical and statistical methods (Kumar Sharma \& Garg, 1998). The domestic bibliographic information statistical analysis tool SATI3.2 was utilized to calculate the number of papers, authors and research institutions, and results were interpreted by bibliometric theories.

Visual Analysis. In this paper, a scientific knowledge graph was drawn with CiteSpace V (Version 5.7 R7 SE (64-bit)), a knowledge visualization software jointly developed by Dr. Chen Chaomei, a Chinese professor at Drexel University in the United States, and WISE Lab, Dalian University of Technology. The 770 documents downloaded were imported into the CiteSpace V software, with the time span set from 1998 to 2008 and the time slice as one slice per year. The different nodes of institution, author and key word were selected. Free from network cutting, the software was directly run to generate the knowledge graph to show the focus, evolutionary process and development trend of sports culture education research. 
Liu, Wang / Analysis of Spatial-temporal Distribution, Focus Trends and Evolution of Sports Culture...

The diachronic distribution of the number of papers can better reflect the dynamic development process of a research topic (Nie Lv \& Zheng, 2013). The number of bibliographies on sports culture education research in China is shown in Figure 1. The number of papers published in the past 20 years shows a wave-like growth trend, which can be roughly divided into three stages. 1) 1998-2007. In the decade, 149 papers on sports culture education were published, with the 14.9 papers published annually on average, indicating that the sports culture education did not attract the attention of researchers. 2) 2008-2014. There were 387 related papers were published in the seven years, with the average annual number of papers published as 55.1. Despite a decline in the "post-Olympic era", this downward trend has been rapidly reversed since 2011. The strategy of cultural power is a highlight of the necessity of sports culture education. 3) 2015-2018. in the four years, 235 papers on sports culture education were published, with 58.7 papers published annually on average. In the "13th FiveYear Plan" for sports development, the necessity of sports culture education and long-lasting arduous efforts required were highlighted.

\section{Spatial-temporal Distribution of Sports Culture Education Research in China}

\section{Analysis of temporal distribution}

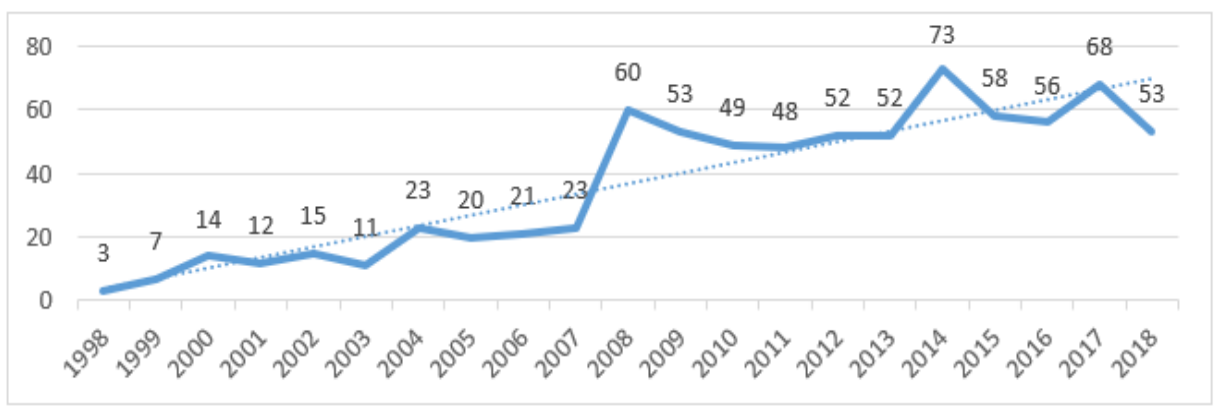

Figure 1. The annual trend of research papers on sports culture education in China published on CSSCI

\section{Analysis of spatial distribution}

According to the literature statistical analysis by SATI 3.2, a total of 1,268 researchers and 668 research institutions conducted research on sports culture education in China from 1998 to 2019. Li Jie pointed out that the cooperation between authors is considered to be a micro level, the cooperation between institutions to be a meso level, and the cooperation between countries (regions) to be a macro level.

Micro-level analysis. Since 1998, most papers on sports culture research were published by Wang Jian. The calculation formula of the core author in Price law is $M=0.749\left(N_{\max }\right)^{1 / 2}$, where $M$ is the number of papers, and $\mathrm{N}_{\max }$ is the number of papers whose author published the most papers in the corresponding year. When the number of papers published by one author is above $\mathrm{M}$, the author is called the core author. According to the statistical results, the value of $\mathrm{N}_{\max }$ is 7 . Introduce it into the formula, leading to the $\mathrm{M}$ value of 1.98 . It can be considered that the author who published two or more papers has become the core author in the sports culture 
Liu, Wang / Analysis of Spatial-temporal Distribution, Focus Trends and Evolution of Sports Culture...

$\overline{\text { education field, which totals 187. Due to space limitations, Table } 1 \text { presents high-yield authors with } 4 \text { or more }}$ published papers in the field of sports culture education. Price law also stipulates that the core authors in a research field should be able to publish $50 \%$ of all papers in the field. In the field of sports culture research, the number of papers published by core authors is 410 , accounting for $53.2 \%$ of the total number of papers published, which has met the requirements of $53.2 \%$ in the number of publications. It shows the long-term concern of Chinese researchers for the sports culture research. There are 22 researchers who published 4 or more papers on the sports culture education as the first author, including 11 from the normal colleges and universities, indicating the backbone role of normal colleges and universities in the study of sports culture education.

Table 1

High-yield Authors in the Sports Culture Education Research in China

\begin{tabular}{clcclc}
\hline Rank & \multicolumn{1}{c}{ Author } & $\begin{array}{c}\text { Number of } \\
\text { publications }\end{array}$ & Rank & \multicolumn{1}{c}{ Author } & $\begin{array}{c}\text { Number of } \\
\text { publications }\end{array}$ \\
\hline 1 & Wang Jian & 7 & 12 & Zhang Rui & 4 \\
2 & Mao Zhenming & 6 & 13 & Ji Liu & 4 \\
3 & Duan Jianzhi & 6 & 14 & Liu Minhang & 4 \\
4 & Han Dan & 6 & 15 & Zhou Xuerong & 4 \\
5 & Qiu Pixiang & 5 & 16 & Lin Xinmao & 4 \\
6 & Yao Lei & 5 & 17 & Zhang Jianhua & 4 \\
7 & Wang Gang & 5 & 18 & Zhao Gang & 4 \\
8 & Tian Yupu & 5 & 19 & Ren Lianxiang & 4 \\
9 & Deng Xinghua & 4 & 20 & Lu Changfen & 4 \\
10 & Yang Ling & 4 & 21 & Xiong Xiaozheng & 4 \\
11 & Gong Zhengwei & 4 & 22 & Zhang Jianhua & 4 \\
\hline
\end{tabular}

Note: Statistics on high-yield authors who published more than 4 papers as the first author

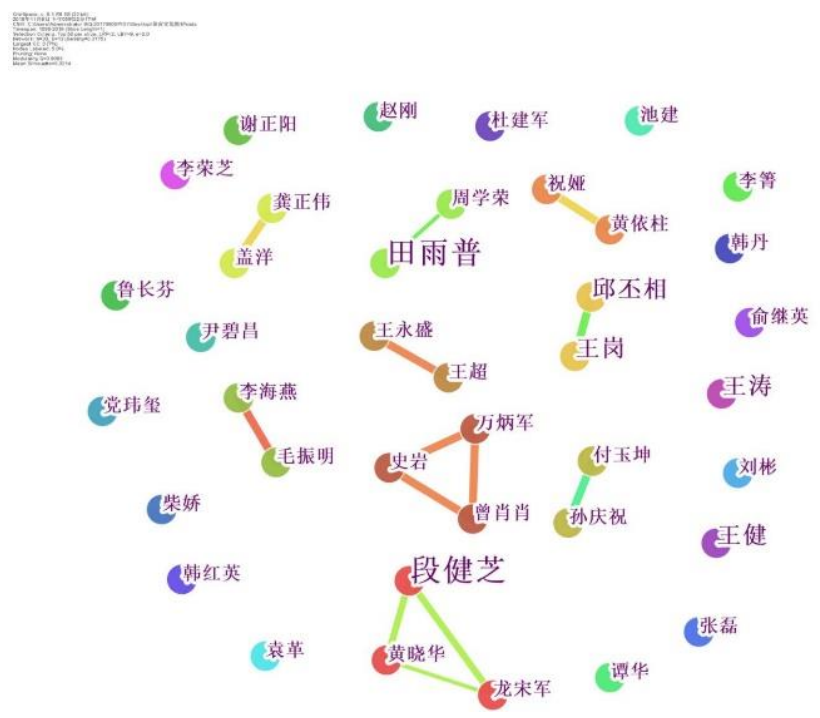

Figure 2. Co-occurrence network of authors in the sports culture research in CSSCI

Run CiteSpace V, the visual analysis software, with the network node selected as "Author" and the relevant thresholds adjusted to generate the co-occurrence network of the authors in the sports culture education research 
Liu, Wang / Analysis of Spatial-temporal Distribution, Focus Trends and Evolution of Sports Culture...

sector in China (Figure 2). It can be seen from the graph that the nodes of author in the sports culture education research field are relatively scattered. At present, two triples of authors take shape, namely one group of Wan Bingjun, Shi Yan and Zeng Xiaoxiao and the other team of Duan Jianzhi, Huang Xiaohua, and Long Songjun. The rest are couples, such as Tian Yupu and Zhou Xuerong, Qiu Pixiang and Wang Gang, Mao Zhenming and Li Hai, etc. There are six small-scale research cooperation groups, while a large number of researchers are independently engaged in relevant research on sports culture education.

Table 2

Core Scientific Research Institutions in the Sports Culture Education Research in CSSCI

\begin{tabular}{clc}
\hline Rank & \multicolumn{1}{c}{ Research institution } & $\begin{array}{c}\text { Number of } \\
\text { publications }\end{array}$ \\
\hline 1 & Beijing Sport University & 17 \\
2 & School of Physical Education, Northeast Normal University & 13 \\
3 & School of Sports Science and Physical Education, Nanjing Normal University & 11 \\
4 & School of Physical Education, Central China Normal University & 9 \\
5 & Shenyang Sport University & 8 \\
6 & School of Physical Education, Soochow University & 7 \\
7 & School of Physical Education and Health, East China Normal University & 6 \\
8 & School of Physical Education and Sports Science, South China Normal University & 6 \\
9 & School of Physical Education, Henan University & 6 \\
10 & School of Physical Education, Northwest Normal University & 5 \\
11 & School of Physical Education and Sports, Beijing Normal University & 4 \\
12 & Guangzhou Sport University & 4 \\
13 & School of Physical Education, Guizhou Normal University & 4 \\
\hline
\end{tabular}

Meso-level analysis. Through the institution analysis by SATI3.2, it was found that 668 scientific research institutions participated in the related research on sports culture education. According to the definition of core institutions in the Price law, the value of $\mathrm{N}_{\max }$ is 17 , which can be introduced to the formula to get the value of $\mathrm{M}$ as 3.08. It can be concluded that institutions with with 4 and more papers published can be identified as the core institutions, totaling 13 (see Table 2). According to Price law, the number of publications issued by core institutions should account for $50 \%$ of the total in the sector. Core institutions in the sports culture education research published 100 papers, accounting for $12.9 \%$ of the total number of papers on the sports culture education in CSSCI, indicating a certain gap to the required number of publications stipulated by the Price Law.

The CiteSpace V software was adopted, with the network node selected as "Institution" and the corresponding thresholds adjusted, to generate the co-occurrence network of the sports culture education research in China (Figure 3). The largest research cooperation network group centers on School of Physical Education of Central China Normal University, and consists of School of Physical Education and Sports Science of South China Normal University, School of Physical Education and Health of East China Normal University, School of Physical Education of Hebei Normal University, and School of Physical Education of Guizhou Normal University, followed by the group of School of Physical Education of Northeast Normal University, Shenyang Sport University, School of Physical Education and Sports of Beijing Normal University, and School of Physical Education of Liaoning Normal University. The third largest group centers on Beijing Sport University and consists of School of Physical Education of Henan University, and School of Physical Education of Jiangxi Normal University. In the largest group, the centrality value of the School of Physical Education of Central China Normal University and the School of Physical Education and Sports Science of South China 
Liu, Wang / Analysis of Spatial-temporal Distribution, Focus Trends and Evolution of Sports Culture...

Normal University are both 0.01 , with that of the rest all as 0. Due to the importance of the the nodes for central measure in the network, nodes with high betweenness centrality are usually the key hubs connecting two different fields (Wu, 2002). This demonstrates that the School of Physical Education of Central China Normal University and the School of Physical Education and Sports Science of South China Normal University occupy an important position in the study of sports culture education. However, from the perspective of their central values, their relevant research institutions on sports culture education have not developed a relatively fixed research partnership.

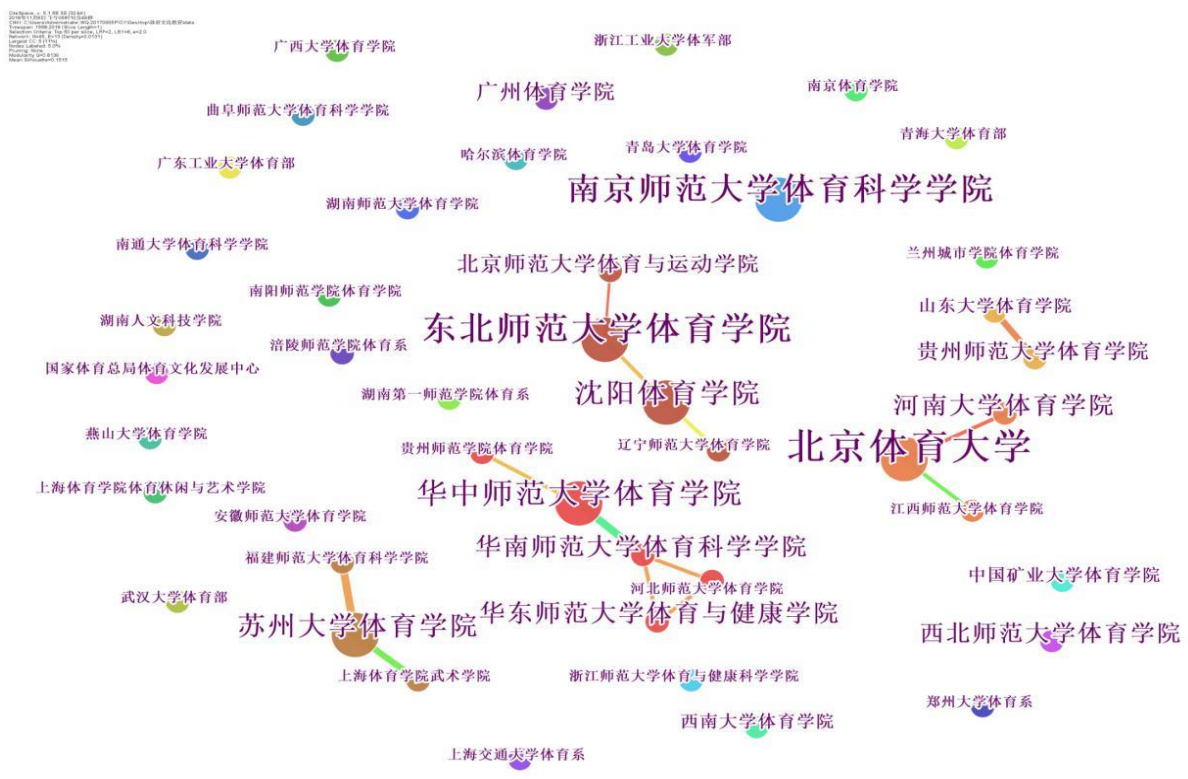

Figure 3. The co-occurrence network of the sports culture education research in China

\section{Focus of the Sports Culture Education Research}

Table 3

\begin{tabular}{clcclc}
\multicolumn{6}{c}{ High-frequency Key Words in the Sports } \\
\hline \multicolumn{1}{c}{ Keylture Education Research in China } \\
\hline Rank & \multicolumn{1}{c}{ Frequency } & Rank & Key word & Frequency \\
\hline 1 & Physical education & 106 & 14 & University Sports & 19 \\
2 & Sports culture & 86 & 15 & development & 18 \\
3 & School sports & 82 & 16 & education & 16 \\
4 & National traditional sports & 50 & 17 & campus culture & 15 \\
5 & Sports & 40 & 18 & Campus sports culture & 14 \\
6 & Physical education curriculum & 37 & 19 & Mass sports & 14 \\
7 & Colleges and university & 32 & 20 & Sports activities & 13 \\
8 & China & 30 & 21 & Physical education colleges & 12 \\
9 & Sports management & 23 & 22 & Teenagers & 12 \\
10 & Physical teaching & 23 & 23 & College Students & 12 \\
11 & College sports & 22 & 24 & Quality education & 12 \\
12 & Sports history & 22 & 25 & Martial arts & 12 \\
13 & Competitive sports & 22 & 26 & Physical education teachers & 12 \\
\hline
\end{tabular}

Note. Statistics on key words with a frequency of over 10 times 
Liu, Wang / Analysis of Spatial-temporal Distribution, Focus Trends and Evolution of Sports Culture...

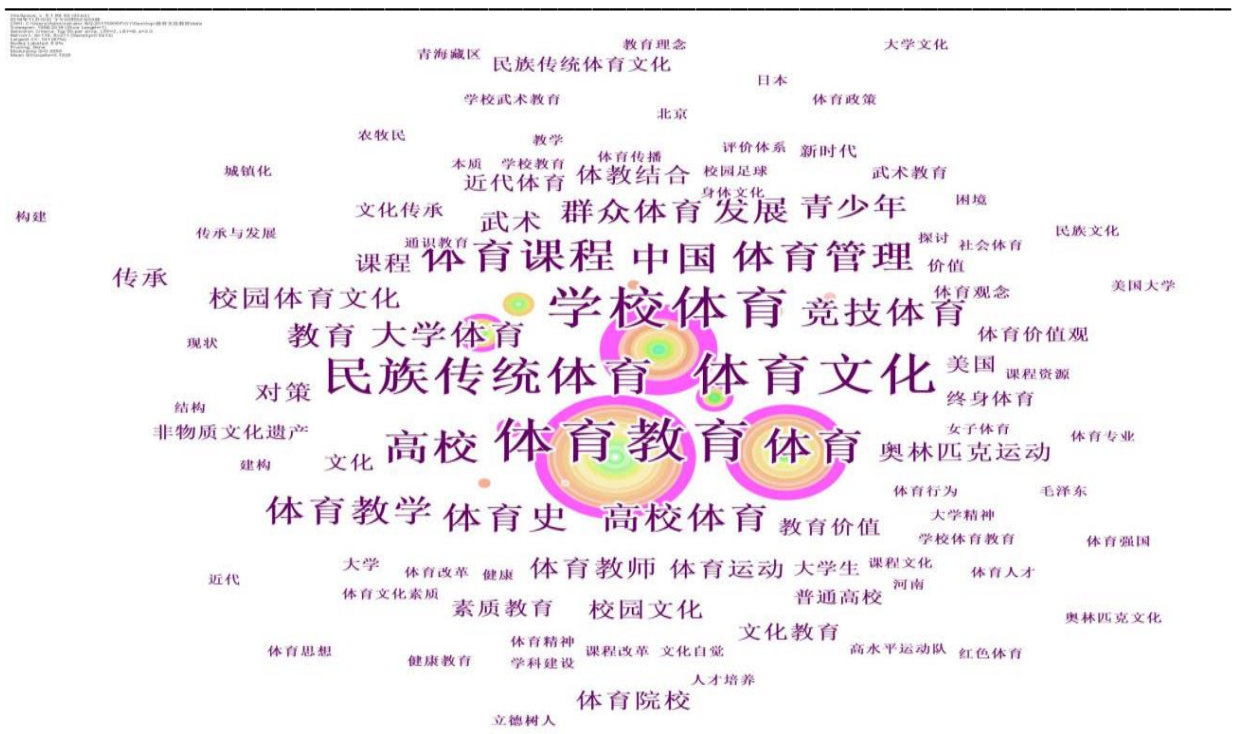

Figure 4. The co-occurrence network of key words in the sports culture education research in CSSCIA

The SATI3.2 was used to extract the key words and calculate the frequency in 770 papers. 1711 keywords were obtained, and 26 keywords occurred more than 10 times (see Table 3). The CiteSpace V visual analysis software was adopted, with "Key word" selected as the node, to draw the co-occurrence network of key words in the research on sports culture education in China (see Figure 4).

According to Table 3 and Figure 4, the following can be concluded. 1) Physical education, physical education curriculum, physical teaching, education, and quality education rank the $1^{\text {st }}, 6^{\text {th }}, 10^{\text {th }}, 16^{\text {th }}$ and $24^{\text {th }}$ in the frequency respectively. Physical education is an important means of school education curriculum; the reform and optimization of physical education curriculums is the content of continuous research in the development of physical education; physical teaching is the process of purposeful, organized and planned training of students according to the standards of teaching curriculum; quality education is the fundamental purpose and the goal of sports culture education. 2) The frequency of sports culture, national traditional sports, sports history and martial arts rank the $2^{\text {nd }}, 4^{\text {th }}, 12^{\text {th }}$ and $25^{\text {th }}$ respectively. Martial arts are the most outstanding performance of traditional national sports; sports history plays an important role in the exploration, protection and inheritance of outstanding national traditional sports; national traditional sports, as an important component of Chinese traditional sports culture, is a unique spiritual gene and spiritual identity of the Chinese nation (Cui and Sun, 2018). 3) The frequency of school sports, college sports, campus culture, and campus sports culture rank the $3^{\text {rd }}, 11^{\text {th }}, 17^{\text {th }}$ and $18^{\text {th }}$ respectively, indicating the constant attention from relevant researchers on the school sports. "The school education follows the health-first guiding ideology", reflecting the importance that the country attaches to school sports. 4) The frequency of sports management, competitive sports and mass sports rank the $9^{\text {th }}, 13^{\text {th }}$ and $19^{\text {th }}$ respectively. The competitive sports, mass sports, school sports and sports culture shall be developed coordinately. In terms of competitive sports, the new historical tasks, goal, mission, and innovative path should be analyzed and explored (Yang and Peng, 2018). 


\section{Historical Evolution and Development Trend of Sports Culture Education Research}

Researchers' study on sports culture education is also a historical process of dynamic evolution. Based on the cluster analysis of key words, the co-occurrence network of the temporal changes in the focus of the sports culture education research in China (Figure 5) can be obtained by selecting "Timezone View" in the "Layout" interface of CiteSpace V visual analysis software.

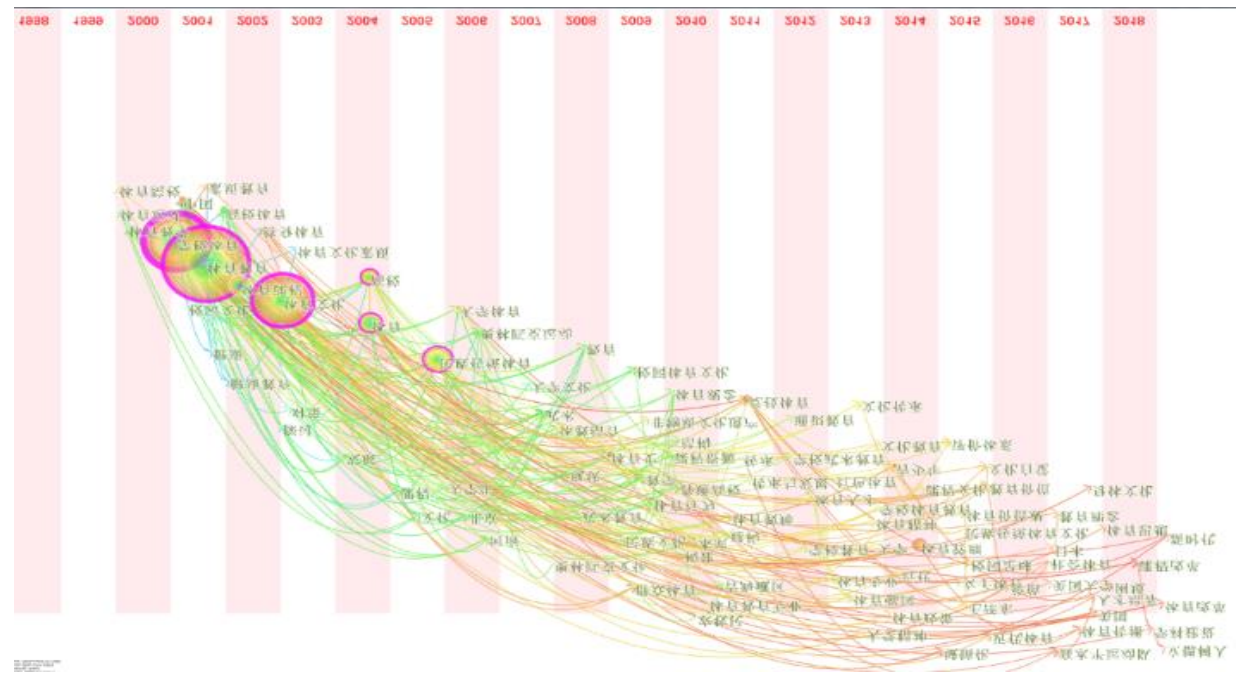

Figure 5. Visual co-occurrence network of the temporal changes in the focus of the sports culture education research in CSSCI

1) In 1998-2003, researches on sports culture education was in the initial exploration period, mainly focusing on the "quality education". During this period, as the compulsory education was basically popularized, colleges and universities expanded the enrollment scale. It was proposed to effectively strengthen the physical education, analyze the connotation of health-oriented education, and begin the reform of college physical education (Wu, 2002) so as to understand the status quo of quality education to further explore the reform path and method, carry out the characteristic campus sports cultural activities (Gong Mao and Wu, 2002), and build a comprehensive physical education system of colleges and universities throughout the entire educational process (Zhang Yu and $\mathrm{Xu}, 2002$ ).

2) In 2003-2008, competitive sports, Olympic sports, and national traditional sports became the new growth points in the study of sports culture education. On the eve of the Beijing Olympic Games, the three major themes of "Environment-friendly Olympics, Culture-enriched Olympics and Technology-empowered Olympics" were interpreted (Sun, 2003) to study the connotation of the Olympic education heritage. The Olympic Games brought good educational opportunities, in which the Olympic education for youth (Ma, 2003) became a focus and an important part in the college sports. During the Olympic Games, the Chinese nation's excellent culture was promoted, and the value of national traditional sports was gradually explored (Hu and Yao, 2005). The 
Liu, Wang / Analysis of Spatial-temporal Distribution, Focus Trends and Evolution of Sports Culture...

$\overline{\text { Olympic Games provided a stage for the traditional Chinese sports culture and new development for the }}$ traditional sports.

3) In 2009-2014, researches focused on sports history, mass sports, intangible cultural heritage, sports power, sports management, sports policy, school sports and university spirit, etc. to further promote the extensive development of sports culture education in China, analyze the differences in sports cognition between Chinese and Western education, and explore the protection and development of traditional national sports from the perspective of intangible cultural heritage. Based on the resource dependence theory and structuration theory (Lu Ding and Bai, 2014), the endangered state of national traditional sports as an intangible cultural heritage was evaluated. In the field of mass sports, the participation of rural residents in the national fitness exercise was surveyed. In the sector of school sports, research focused on the reform, facility policy, and cultural value of school sports.

4) In 2015-2018, researches on sports culture education focused on the new era, sports reform, discipline establishment, talent cultivation by morality, cultural consciousness and campus football. The researchers put forward their own ideas around the top design, path selection, and youth training of campus football and football culture, explored the revitalization of sports value and responsibility of sports in the university as well as the setting of physical education curriculum in terms of the preference of sports doctoral enrollment, examined the predicament of talent cultivation by morality in college sports teaching, reflected on the development of school sports, and found out the path of school sports reform and development. It has been the focus of the school sports education research in the new era to cultivate students' social adaptability through physical education curriculum reform.

In summary, researches on sports culture education evolve with the times, which is manifested in the following aspects. On the one hand, school sport is a long-term topic in the sports culture education research, which undertakes more in-depth exploration in related issues from the macro to micro level. On the other hand, relevant researchers have recognized that sports culture education is not limited to the school sports level but also includes competitive sports and mass sports, which means sports culture education is a huge project that benefits the entire population.

\section{Conclusion}

The statistics on the number of papers on sports culture education show that that number in China shows an overall growth trend and reached a peak in 2014. Despite a slight decline afterwards, the number still remained high. It can provide an important theoretical support for the implementation of sports culture education during the "13th Five-Year Plan" period.

From the perspective of the authors and scientific research institutions of sports culture education research, normal colleges are the main force. In the related research on sports culture education, high-yield authors and research institutions with certain influence have been identified. In terms of the cooperation network, the authors and research institutions in the sports culture education have not developed a stable research cooperation network group. This shows that the exchange and cooperation between the authors and scientific research 
Liu, Wang / Analysis of Spatial-temporal Distribution, Focus Trends and Evolution of Sports Culture...

institutions should be actively promoted, which is of great significance for solving the dilemma that arises in the sports culture education in China.

With respect to the research focus and evolutionary process, the researches on sports culture education in China mainly focus on school sports with the longest research history. With the continuous advancement of the society, the study of sports culture education has gradually transferred its focus to competitive sports, mass sports and sports management, with more comprehensive research perspectives, more diverse research methods, and more profound research contents. Sports culture education is a concrete and systematic and project that benefits the entire population and requires the coordination and cooperation of school sports, competitive sports and mass sports in an all-round way.

\section{References}

Cui, L. Q., \& Sun, X. H. (2018). Theory and practice of the inheritance and development of Chinese excellent traditional sports culture: An interpretation of "on the views of the implementation of Chinese excellent traditional culture inheritance project". Journal of Beijing Sport University, 41(1), 126-132. https://dx.doi.org/10.19582/j.cnki.11-3785/g8.2018.01.018

Gong, D. G., Mao, Z. H., \& Wu, B. Y. (2002). Discussion on significance of sports culture and campus culture construction. Journal of Beijing Sport University, (2), 170-172. https://dx.doi.org/10.3969/j.issn.10073612.2002.02.010

Hu, Y. N., \& Yao, J. B. (2005). The humanistic connotation and ethical education function of national traditional sports. Journal of Beijing Sport University, (8), 1023-1025. https://dx.doi.org/10.3969/j.issn.1007-3612.2005.08.005

Kumar, S., Sharma, P., Garg, K. C. (1998). Lotka's law and institutional productivity. Information Processing \&Management, 34(6), 775-783. https://dx.doi.org/10.1016/S0306-4573(98)00027-2

Lu, P. J., Ding, X. Q., Bai, J. X. (2014). An empirical study of endangered status evaluation of intangible cultural heritage in traditional ethnic sport. China Sport Science, 34(11), 16-26. https://dx.doi.org/10.3969/j.issn.1000-677X.2014.11.002

Ma, Y. L. (2003). Analysis on the olympic education problem of Chinese teenagers before Peking Olympic games. Journal of Sport \& Science, (2), 11-13. https://dx.doi.org/10.3969/j.issn.1004-4590.2003.02.004

Nie, Y. J., Lv, W. G, Zheng, X. P. (2013). Analysis on the present research situation of sports culture at home and abroad based on the knowledge domains map. Journal of Chengdu Sport University, 39(11), 26. https://dx.doi.org/10.3969/j.issn.1001-9154.2013.11.006

Sun, B. L. (2003). A probe into the three themes of Olympic Beijing 2008. Social Science of Beijing, (1), 2834. https://dx.doi.org/10.3969/j.issn.1002-3054.2003.01.006

$\mathrm{Wu}, \mathrm{H}$. Y. (2002). Quality education and reform of physical education in colleges and universities. Journal of Shanghai Physical Education Institute, (1), 203-204.

Yang, G. Q., \& Peng G. Q. (2018). Study on strategic mission and innovation path of china's competitive sports in the new era. China Sport Science, 38(9), 3-14,46. 
Liu, Wang / Analysis of Spatial-temporal Distribution, Focus Trends and Evolution of Sports Culture...

Zhang, C. Y., Yu, J., \& Xu, Y. J. (2002). Discussion on construction of all-directional physical education system in colleges and universities. Journal of Beijing Sport University, (5), 665-666,671. https://dx.doi.org/10.3969/j.issn.1007-3612.2002.05.034 